\title{
Deleterious Effects of Stress on Time Spent Together and Parents' Relationship Satisfaction
}

\author{
Anne Milek ${ }^{a}$, Ashley K. Randall ${ }^{b}$, Fridtjof W. Nussbeck ${ }^{c}$, Christina J. Breitenstein ${ }^{d}$, \\ and Guy Bodenmann ${ }^{d}$ \\ aDepartment of Psychology, University of Arizona, Tucson, Arizona, USA and Department of Psychology, \\ University of Zurich, Zurich, Switzerland; ${ }^{b}$ Department of Psychology, Arizona State University, Phoenix, \\ Arizona, USA; 'Department of Psychology, Bielefeld University, Bielefeld, Germany; ${ }^{d}$ Department of \\ Psychology, University of Zurich, Zurich, Switzerland
}

\begin{abstract}
Data from 90 German committed heterosexual couples who had a least one child were used to examine the associations between chronic minor external stress, quantity and quality of time spent together as a couple, and partners' relationship satisfaction. Using an extended version of the Actor Partner Interdependence Model, the authors found significant negative indirect effects from mothers' chronic minor external stress via quality, but not quantity, of shared time to both parents' reported relationship satisfaction. Mothers' chronic minor external stress was associated with fewer reported quality time activities, which were also associated with lower reports of relationship satisfaction for both mothers and fathers. The authors did not find indirect effects for fathers' chronic minor external stress. Overall, the frequency of quality time activities may be more important for mothers, as it explained $25 \%$ of variance in their relationship satisfaction, compared with $15 \%$ in fathers' relationship satisfaction. Implications for relationship researchers and clinicians are discussed.
\end{abstract}

\section{KEYWORDS}

Dyadic data analysis; marital satisfaction; parenthood; relationship maintenance; stress

The time couples spend together-shared time-is not only crucial for relationship quality (Crawford, Houts, Huston, \& George, 2002; Holman \& Epperson, 1984; Orthner, 1975) but also an important maintenance strategy for relationship satisfaction and stability (Baxter \& Dindia, 1990). It is not clear, however, how much the mere amount of time spent together (quantity) contributes to a satisfying relationship, or whether it is how time is spent (quality) that predicts relational outcomes. Moreover, there are a number of factors that could contribute to the quantity and quality of the time partners spend together, such as the experience of stress. More than two-thirds of couples report a lack of time for their partner and family (Jurczyk \& Heitkötter, 2012; Matos \& Galinsky, 2010; Roxburgh, 2006), which may be due in part to enduring everyday stress that partners face outside their relationship, defined as chronic minor external stress (CMES) (Randall \& Bodenmann, 
2017, 2009). Chronic minor external stressors (e.g., driving to work during rush hour every day) contribute to a feeling of being pressured for time (Levine, 1997). The lack of time may be especially true for working mothers and fathers, who are struggling between conflicting responsibilities in their different domains of life (e.g., work demands, child care; Gershuny, 2000; Hochschild, 1997).

Effects of external stress can spill over into one's relationship, causing partners to experience decreases in effective communication, which can ultimately have negative effects on relational well-being over time (Randall \& Bodenmann, 2009, 2017). The stress-divorce model proposed by Bodenmann (2000; see also Bodenmann et al., 2007) suggests that deteriorated shared time may be another pathway that explains how external stress can negatively affect relationship satisfaction. For example, the chronic experience of minor everyday stressors may impact the time shared between partners as they are busy navigating these stressors (e.g., dealing with a demanding work schedule while taking care of the children). Given the increased stress parents may face (Hamermesh, 2000; Roxburgh, 2002, 2006; Wight, Raley, \& Bianchi, 2008; Witt \& Goodale, 1981) and the importance of the time spent with one's romantic partner for relational outcomes (Hill, 1988; Holman \& Jacquart, 1988; Orthner, 1975), it is surprising that limited literature exists that focuses on understanding how parents' shared time is associated with daily hassles and minor external stress.

The present study addresses this gap by examining how CMES is associated with parents' shared time (in quantity and quality) and their reported relationship satisfaction. First, we examined how shared time may mediate the association between parents' CMES and relationship satisfaction. Second, we examined the unique contribution of (a) quantity and (b) quality of shared time in explaining relationship satisfaction. Third, based on literature to suggest women are more affected by time pressures (e.g., Hamermesh, 2008) and attach more importance to time with one's partner (e.g., Smith, Synder, Trull, \& Monsma, 1988) compared with men, we examined gender differences regarding the associations between CMES, dimensions of shared time, and relationship satisfaction for women (mothers) and men (fathers) who have at least one child.

\section{Shared Time and Relationship Satisfaction: Quantity Versus Quality}

Early studies have suggested that simply spending a certain amount of time in joint activities (time quantity) is related to less marital disagreement (Hatch \& Bulcroft, 2004), higher marital satisfaction (Kilbourne, Howell, \& England, 1990; Kingston \& Nock, 1987; Miller, 1976; Orthner, 1975), higher marital happiness (Kirchler, 1988; White, 1983), and overall marital stability (Hill, 1988). Recent research has argued, however, that it is not merely the amount of time partners spend together but rather the quality of the time spent together that matters most for relational outcomes: researchers have detected only small effects-if any-of amount of hours spent together on relationship outcomes (e.g., Berg, Trost, Schneider, \& Allison, 2001; Johnson, Zabriskie, \& Hill, 2006). However, highly interactive joint quality time activities were found to beneficial for relationships, as they provide a context for 
promoting positive communication and mutual self-disclosure (e.g., Flora \& Segrin, 1998).

Aron and Aron (1986) suggest that increasing the amount of time together without taking the quality of time into account may even have negative relational consequences for the couple, triggering habituation processes and leading to boredom with each other's company. Their research has shown that reasoning: participation in activities that are self-expanding, such as those that are novel and exiting, were found to have a positive effect on relationship quality over and above any effect of shared participation in more mundane activities (Aron, Norman, Aron, McKenna, \& Heyman, 2000; Reissman, Aron, \& Bergen, 1993). Zabriskie and McCormick (2001) propose that families should use less frequent balance activities (e.g., musical performance, outdoor recreation like camping) and common or informal core activities (e.g., eating dinner or exercising together) to successfully function as a system, arguing that both types of activities are essential to meet opposing needs of stability and change.

\section{Effects of External Stress}

Individuals are exposed to external stressors in various domains and forms, which can spill over into their romantic relationship (Neff \& Karney, 2004; Repetti, Wang, \& Saxbe, 2009). Coping with external stressors might deplete couples' resources (Buck \& Neff, 2012), increase couple conflict (Ledermann, Bodenmann, Rudaz, \& Bradbury, 2010), and reduce the time couples overall spent together (Bodenmann, 2000). For example, partners may have to synchronize conflicting work hours or "bring their work home" to meet greater work demands (e.g., project deadlines), and account for family demands, such as getting their children to school or to various appointments (Gershuny, 2000; Hochschild, 1997). In several studies assessing the subjective perception of time stress, about two-thirds of the women and men report a shortage of time spent with their spouse and children (Daly, 2001; Matos \& Galinsky, 2010; Roxburgh, 2006). Although Voorpostel, van der Lippe, and Gershuny (2010) showed that the time spent in shared spousal leisure activities has increased during the past decades, Dew (2009) demonstrated that the overall amount of time partners budget for one another has significantly decreased. On average, married individuals in 2003 spent approximately 50 minutes less per day alone with their spouses compared with married individuals in 1973. In addition, increased participation in the labor force (Amato, Booth, Johnson, \& Rogers, 2007) as well as (time) intensive parenting norms (Dew, 2009) have led parents, specifically those with young children, feeling "permanently stressed" (e.g., Hamermesh, 2000; Holman \& Epperson, 1984; Roxburgh, 2006).

One spouse's experience of external stress also affects their partner's experience of stress due to the partner's shared interdependence, subsequently turning the individual experience of stress into dyadic stress (Bakker et al., 2005; Bodenmann, 1995; Randall \& Bodenmann, 2017). Relational scholars suggest that stress undermines close relationships by disrupting adaptive and positive interpersonal processes (e.g., 
Conger et al., 1990; Karney \& Bradbury, 1995; Randall \& Bodenmann, 2009); spending less time together as a couple may be one of them (Bodenmann, 2000). Indeed, Holman and Jacquart (1988) have found that for wives-not husbands-reporting high versus low levels of stress changed the magnitude of the positive association between leisure activities and marital satisfaction. They suggested that the association between stress, leisure time, and marital satisfaction is a "fruitful area for further study" (Holman \& Jacquart, 1988, p. 76). Several earlier studies investigated leisure time during stages of (stressful) family life cycles (Kelly, 1975, 1980; Orthner, 1975; Witt \& Goodale, 1981); however, since 1988, only a handful of studies have followed that suggestion using parental samples. For example, Claxton and Perry-Jenkins (2008) identified shared leisure time as integral to well-functioning marriages throughout the transition to parenthood, a critical life event most likely highly increasing couples' everyday stress levels. Empirical support directly assessing to which extent chronic minor external stressors (e.g., daily hassles) affect parents' shared time is still lacking, however.

During times characterized by CMES, parents are likely to (a) spend less time in pursuing joint activities they otherwise use as bonding recreation (Huston, McHale, \& Crouter, 1986), (b) deviate from everyday routines (Bodenmann, 2000), and (c) invest more time in task-oriented, problem-focused activities (cf. Bianchi, 2000; Lenz, 2009). In addition, individual coping behaviors, like withdrawal and rumination (King \& DeLongis, 2014), may also lead to less self-disclosure between partners, creating an atmosphere of misunderstanding and tension and fostering more negative dyadic interactions (Repetti, 1989). Therefore, partners' quantity and quality of shared time may be impaired because of chronic external stress. As such, couples may experience mutual alienation and decreases in relationship satisfaction, which over time could lead to an increased likelihood for divorce, as the accumulation of external stress has been found to be a significant predictor for the decision to end the relationship (Bodenmann et al., 2007).

Given the potentially severe consequences on intimate relationships, psychoeducation of the influence of stress on couples is considered an essential technique in couple therapy aimed at increasing (a) the awareness of how chronic minor external stressors affect a relationship and raise the likelihood for arguments, alienation, and dissatisfaction and (b) the mutual understanding and acceptance by explaining how partners may differentially react to stress based on individual factors (e.g., personality, prior experiences, personal schemata, etc.) (Milek \& Bodenmann, 2016). From a clinical point of view, further insights into the different time related mechanisms of the stress spillover process may offer new avenues for couple interventions (cf. Fraenkel, 2001).

\section{Gender Differences for the Importance of Shared Time}

Perceptions of time spent together are known to correlate only moderately between spouses (Claxton \& Perry-Jenkins, 2008; Gager \& Sanchez, 2003), and women and men differ in the extent to which shared time can explain variability in relationship outcomes (e.g., Holman \& Jacquart, 1988; Smith et al., 1988). Women seem 
to attribute more importance to shared time. Furthermore, women and men are differentially affected by and respond differently to stress (Hamermesh, 2008; Tamres, Janicki, \& Helgeson, 2002). In several studies, women report more somatic symptoms and scored higher on emotion-focused coping styles in the presence of stress, whereas men show more withdrawal and preferred problem-focused coping styles (Coyne \& Smith, 1991; Gottlieb \& Wagner, 1991; Matud, 2004). Given these gender differences, it is reasonable to assume that associations between CMES, shared time and relationship satisfaction may be different for mothers and fathers.

\section{The Current Study}

According to the stress-divorce model (Bodenmann et al., 2007), external stress can spillover into the relationship deteriorating partners' relationship satisfaction by means of impaired shared time; however, to date, few studies have empirically examined this mechanism. The purpose of the present study was three-fold. First, we examined mediating mechanisms of shared time. Based on the stress-divorce model (Bodenmann et al., 2007), we predicted that quantity and quality of shared time would mediate the negative relationship between parents' CMES and their relationship satisfaction. More specifically, we tested the following hypotheses:

H1: There will be an indirect effect of mothers' and fathers' CMES on relationship satisfaction via shared time (H1a); mothers' and fathers' CMES thereby being negatively associated with quantity and quality of shared time (H1b) and time quantity and quality positively associated to relationship satisfaction.

Second, we examined whether time quantity or quality was more strongly associated with mothers' and fathers' relationship satisfaction. Separately, both dimensions have been found to be positively related to couples' marital satisfaction (Berg et al., 2001; Flora \& Segrin, 1998; Holman \& Jacquart, 1988; Kingston \& Nock, 1987; Orthner, 1975), however, only including both aspects of shared time simultaneously will enable us to reliably disentangle how much time quantity and quality contribute to parents' satisfaction in the presence of CMES. Based on empirical findings investigating patterns and types of joint leisure time (Flora \& Segrin, 1998; Holman \& Jacquart, 1988; Johnson et al., 2006; Kingston \& Nock, 1987), we hypothesized:

H2: Quality time will explain more variance in mothers' and fathers' relationship satisfaction than the time quantity.

Third, given that women experience more subjective time pressures and stress than men do (American Psychological Association, 2011; Robinson \& Godbey, 1998) and shared time was found to be more important for women's relationship satisfaction than it was for men's (e.g., Holman \& Jacquart, 1988), we expected to find gender differences in the mediation model and hypothesized:

H3: Associations between CMES, quantity and quality of shared time and relationship satisfaction will be stronger for mothers than for fathers. 


\section{Method}

\section{Participants and Procedure}

All study procedures were approved by the local university ethics committee. Data were collected in 2013 as part of a larger project investigating stress-coping transmission processes between parents and adolescents. Parents were recruited via online relationship forums, university mailing lists, posters, flyers, or handouts disseminated in community centers and local sports clubs in North Rhine-Westphalia, Germany. To be eligible for the current project, couples had to match the following inclusion criteria: both partners had to (a) agree to participate in the study, (b) have at least one child between the age of 16 and 21, (c) currently be in a heterosexual, committed relationship for at least 1 year, and (d) be fluent in German. In total, 100 German-speaking mothers and 95 fathers contacted the research assistants and agreed to participate in the study (matching up to $N=91$ couples). Both couple members were sent an individual code and were asked to fill out a series of online questionnaires independently from one another, which took approximately 30 minutes to complete. Data from 13 participants (four fathers and nine mothers) were excluded because their partner did not complete the questionnaires. Additionally, data of one couple had to be removed as they reported not having children. In total, data from 90 couples (180 individuals) were considered for all analyses in the present study. Participants were between 39 and 68 years old, and mothers were significantly younger than fathers $\left[M_{\text {mothers }}=50.78, S D_{\text {mothers }}=3.82, M_{\text {fathers }}=52.96\right.$, $S D_{\text {fathers }}=5.16$; paired $\left.t(89)=5.07, p<.001\right]$. Mean relationship duration was 25 years $(S D=9.96$, range $=1-41)$ and $87 \%$ of the couples were married. Five couples were living in separate apartments. Couples had up to five children $(M=2.26$, $S D=0.94)$ between 15 and 32 years of age $(M=21.58$ years, $S D=3.29)$. Sixtyseven percent of the couples were either living together with one (34\%), two (28\%), or three $(5 \%)$ children, and $33 \%$ had children who were no longer living at home.

Fourteen mothers (15.6\%) and 23 fathers (25.6\%) reported graduating from college or university, and 75 mothers (83.3\%) and 67 fathers $(74.4 \%)$ had a high school degree. At time of assessment, the majority of mothers (90\%) and fathers (95\%) were employed, with an average weekly work load of $M=25.5$ hours $(S D=13.6)$ for mothers and $M=38.0$ hours $(S D=9.9)$ for fathers [paired $t(88)=8.012, p<.001$ ] The average monthly household salary was equivalent to US $\$ 4,736(M=4,307$ EUR, $S D=1,865$ EUR) and hence comparable to the mean salary of the Western German population in 2013 (4,321 EUR; German Federal Statistical Office, 2015). Parents were not compensated for their participation.

\section{Measures}

Participants provided comprehensive demographic information (e.g., age, relationship duration, marital status, number of children, highest education level, occupation, and employment status) and completed the following measures independently of one another. 


\section{Time Quantity: Amount Of Time Spent Together (Hours/Day)}

Participants were asked to estimate how many hours they spend together with their spouse each day during an average week, based on the prior week. Because the amount of shared time parents spend together may differ on the weekdays versus the weekend (cf. Milek, Butler, \& Bodenmann, 2015) and participants are likely to be more stressed on weekdays compared with weekends (cf. Thorn, Hucklebridge, Evans, \& Clow, 2006), we calculated an overall measure for the reports of time spent together during weekdays by averaging the mothers' and fathers' responses (Monday through Friday). Partners' responses on how many hours they spent together during a weekday were significantly correlated by $r=.71 .{ }^{1}$ On average, couples reported spending approximately 4.84 hours $(S D=2.62)$ on weekdays with each other.

\section{Quality Time}

Participants reported how often they engage in shared activities with their partner (e.g., doing chores, playing games, watching TV, etc.) on a weekly basis from $1=$ never to $5=$ very often. Quality time was operationalized by averaging reports of the weekly frequency of all those couple activities that were rated by more than $90 \%$ of all participants to have the potential to enhance a feeling of togetherness or we-ness within the couple (five items; eating meals together, going out, talking about our day, discussing important issues, being physically affectionate/intimate). On average, couples reported to often spend quality time activities together during a normal week $(M=3.82, S D=0.43)$.

\section{Perceived Chronic Minor External Stress (CMES)}

Individual's subjective evaluation of their CMES load was assessed by using a single item. Mothers and fathers rated the extent to which they had experienced minor stress originating outside their intimate relationship (e.g., daily hassles, quarrels with neighbors, job-related stress, etc.) ranging from $1=$ not at all to $4=a$ lot throughout the past 12 months.

\section{Relationship Satisfaction}

Participants rated their relationship satisfaction using the German version of the Relationship Assessment Scale (RAS; Dinkel \& Balck, 2005; Hendrick, 1988). The measure consists of seven items (e.g., "In general, how satisfied are you with your relationship?") ranging from 1 to 5 . The positively (items 1, 2, 3, 5, and 6) and negatively phrased items (items 4 and 7, reversely coded) were averaged such that higher values represented greater relationship satisfaction. Internal consistency reliability was high for both mothers $(\alpha=.90)$ and fathers $(\alpha=.87)$.

\section{Statistical Analysis}

Actor-Partner-Interdependence Models (APIM; Kenny, 1996; Kenny \& Cook, 1999; Ledermann, Macho, \& Kenny, 2011) were used to test whether shared time mediated the association between CMES and relationship satisfaction (Figure 1). The APIM 


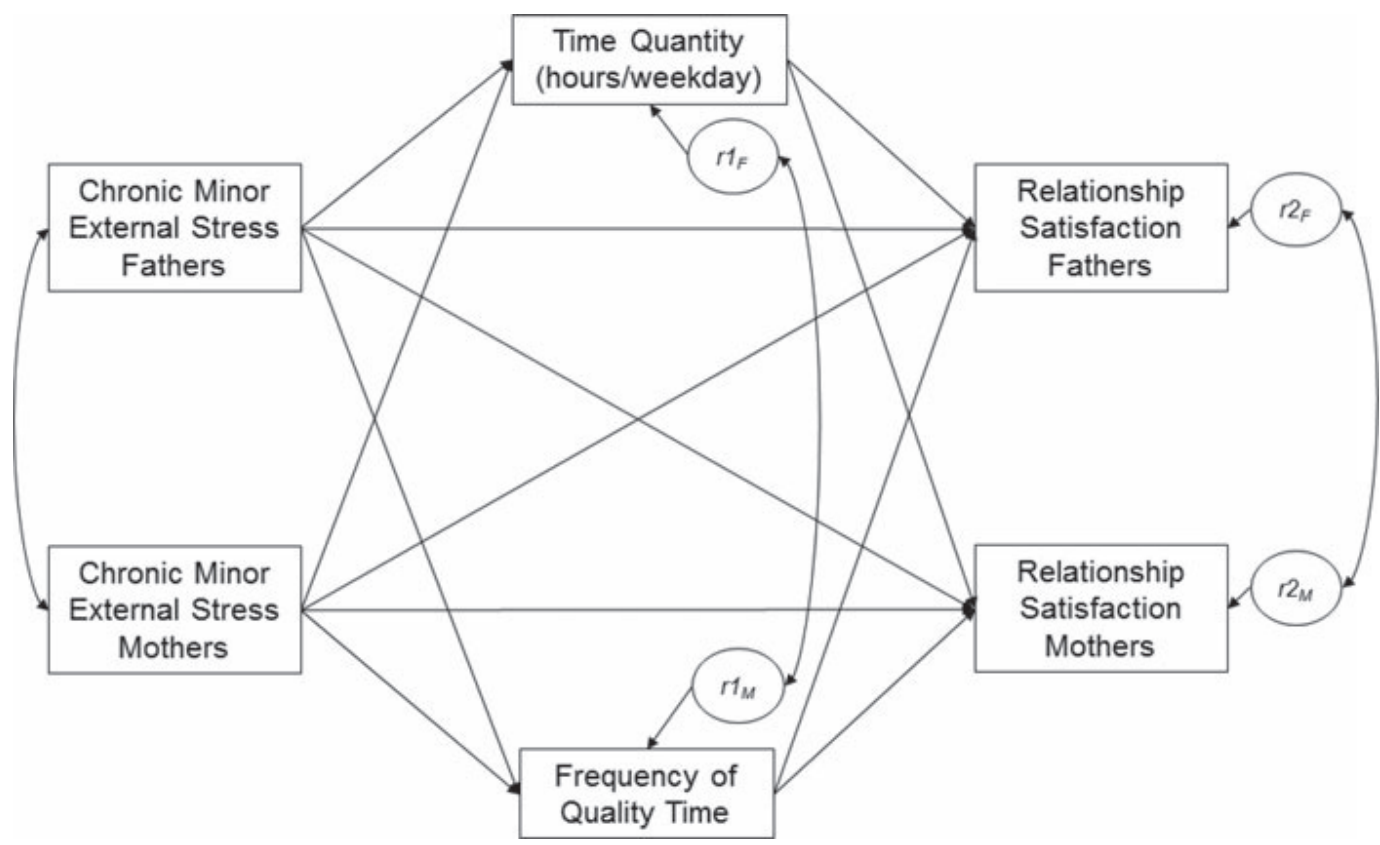

Figure 1. Schematic model of shared time mediating the negative association between chronic minor external stress and relationship satisfaction for fathers and mothers.

approach allows for the identification of specific mediation pathways, as effects of mothers' and fathers' predictors on shared time and both couple members' individual outcomes (i.e., relationship satisfaction) can be estimated simultaneously. In the current project, mediation was said to occur (H1) when the effect of mothers' or fathers' CMES on mothers' or fathers' relationship satisfaction was explained by significant indirect effects via quantity or quality of shared time.

To test whether time quantity or quality was more strongly associated with parents' relationship satisfaction (H2), we compared the $\chi^{2}$ score of a model with freely estimated parameters with the $\chi^{2}$ score of a model in which the paths for time quantity and quality were constrained to be equal. A significant change in $\chi^{2}$ indicated that the association between relationship satisfaction and time quantity differed significantly from the association between relationship satisfaction and quality time. In addition, we relied on the following goodness-of-fit criteria (see Hu \& Bentler, 1999): (a) a nonsignificant $\chi^{2}$, (b) a comparative fit index (CFI) greater than .95 , (c) a root mean square error of approximation (RMSEA) of less than .05, and (d) a standardized root mean square residual (SRMR) of less than .05 to determine the best-fitting model. Furthermore, we tested how much variance of relationship satisfaction above and beyond the other variables in the model is explained separately by the two mediating variables quantity and quality of shared time. To accomplish this, we used the best-fitting model and removed one mediator at a time. As all other variables were still considered in the model, the decrease in the determination coefficient indicated the incremental impact of the removed mediator on relationship satisfaction giving information about effect sizes.

We tested for gender differences (H3) by using the same procedure described here earlier. We compared different models with and without equalized paths for mothers' and fathers' associations between the variables of interest. More specifically, we constrained effects to be equal across gender and compared the $\chi^{2}$ 
value to the model in which the path coefficients were freely estimated. A significant change in $\chi^{2}$ indicated that a path coefficient differed significantly between mothers and fathers.

Analyses were conducted using Mplus 7 (Muthén \& Muthén, 1998-2012). Following recommendations of Shrout and Bolger (2002), the full information maximum likelihood estimation procedure (FIML) with bootstrap option (1000 samples) implemented in Mplus was used to estimate model parameters and corresponding standard errors. Using bootstrapping allows for the approximation of the sampling distribution of the indirect effects to obtain confidence intervals that are more accurate than confidence intervals acquired by using standard methods (Hayes \& Preacher, 2010). If zero is included in the $95 \%$ confidence interval of the bootstrapped indirect effect, the indirect effect is nonsignificant.

Control Variables. Couples with high workload and children are more affected by time scarcity and time stress (e.g., Hamermesh, 2000; Holman \& Epperson, 1984; Roxburgh, 2006). Based on this, we included mothers' and fathers' weekly working hours, number of children living in the household, and mean age of children in addition to relationship duration to control for potential confounds in all models. Effects of these variables could be restricted to be equal across genders without decreases in model fit. To simplify the interpretation of effects and to eliminate nonessential multicollinearity (Aiken \& West, 1991), all predictors were standardized. Covariation between predictor variables and the two mediators was permitted in all models. We did not have missing values for our variables of interest except for female relationship satisfaction (one missing value $=1.1 \%$ ) and male external chronic stress (one missing value $=1.1 \%$ ).

\section{Results}

Means, standard deviations, and bivariate correlations for mothers and fathers among all study variables are presented in Table 1 . Consistent with most studies (e.g., Ledermann et al., 2010), participants reported relatively low levels of CMES and rather high levels of relationship satisfaction. In line with European labor market statistics (Eurostat, 2012), gender differences were found in workload toward mothers working fewer hours per week in a paid job. Mothers and fathers did not differ in any other variables.

As a prerequisite to address any of our hypotheses, we first tested a series of models containing both mediator variables concurrently. Starting with the saturated model allowing all parameters to vary freely between mothers and fathers, we gradually restricted effects of direct paths to be equal across gender to identify the most parsimonious fitting model. The model with equalized paths for associations involving the control variables and freely varying paths for associations involving the mediator variables was the most parsimonious model with excellent fit $\left(\chi^{2}=4.611\right.$, $d f=7, p=.707, \mathrm{CFI}=1.000$, RMSEA $=.000$, SRMR $=.021)$. More restrictive models with identical path coefficients for mothers and fathers for CMES on shared 


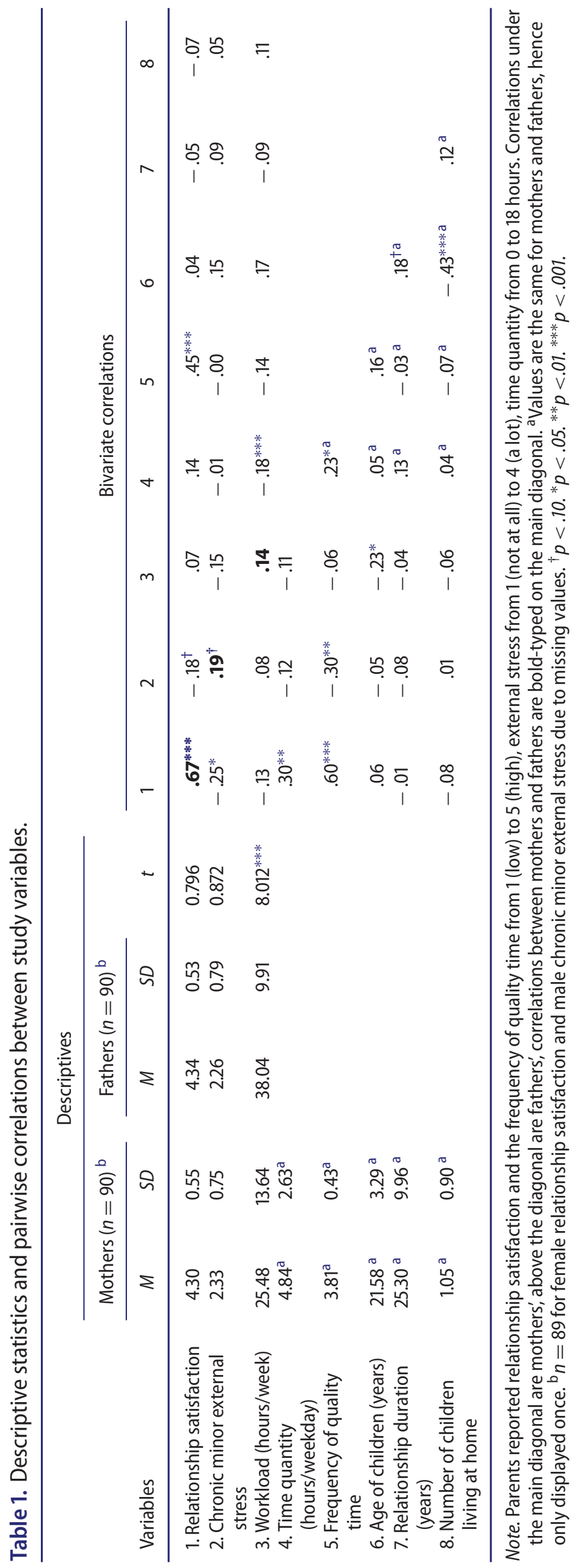


Table 2. Estimates of direct effects and indirect effects (bootstrapped) for a mediated actor-partner interdependence model (APIM; $N=90$ couples).

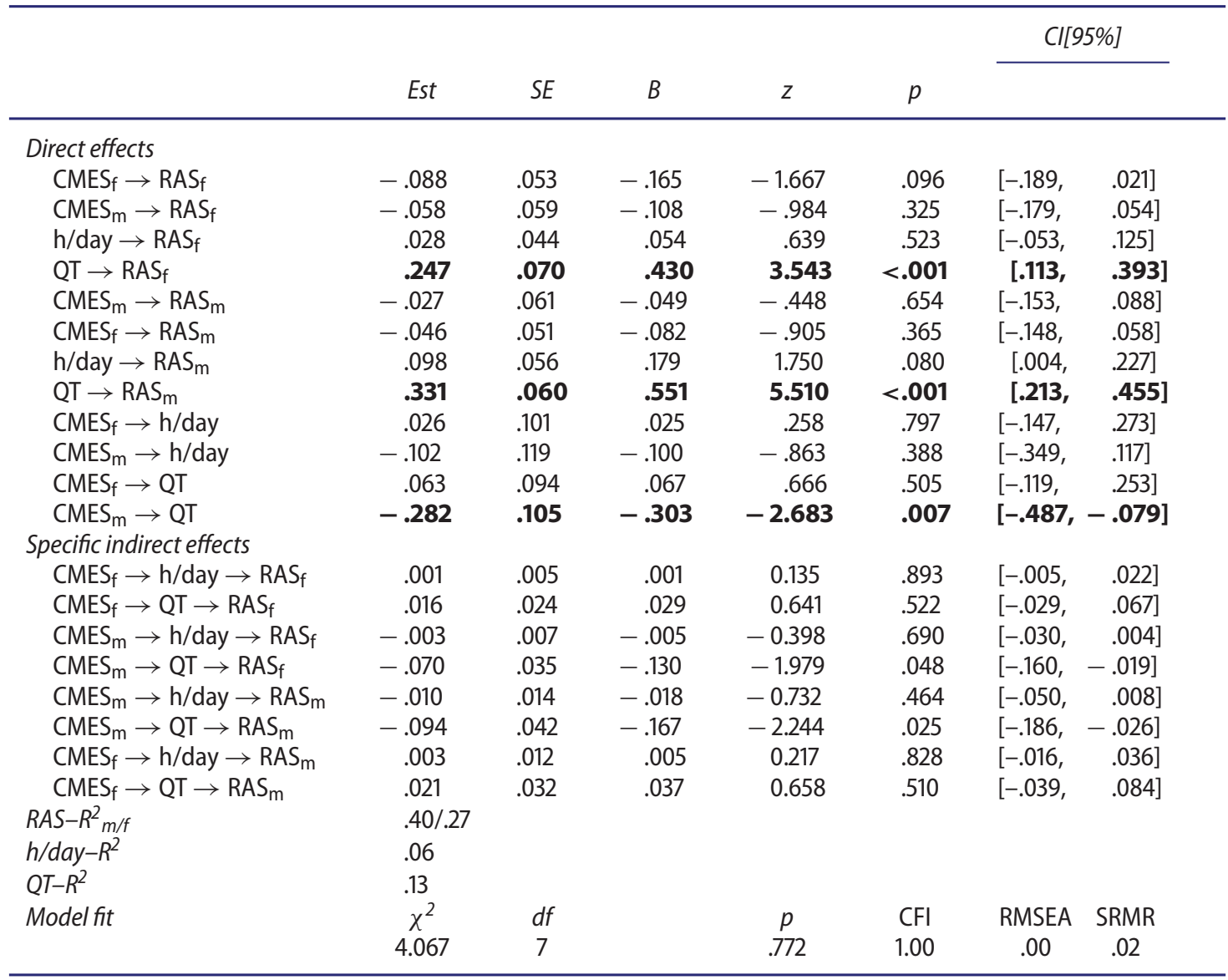

Note. Significant pathways are bold; we controlled for the number of children in the household, the mean age of children, relationship duration and mothers' and fathers' workload; Est = unstandardized estimated, $B=$ standardized estimate, RAS = relationship satisfaction, $\mathrm{h} /$ day $=$ time quantity per weekday, $\mathrm{CMES}=$ chronic minor external stress, $\mathrm{QT}=$ frequency of quality time, $\mathrm{m}=$ mothers, $\mathrm{f}=$ fathers.

time (model $\mathrm{r} 1$ ) or shared time on relationship satisfaction (model $\mathrm{r} 2$ ) revealed model fit indices that partly were below the recommended cut-offs. The (marginally) significant decrease in model fit (model $\mathrm{r} 1: \Delta \chi^{2}=5.228, \Delta d f=2, p=.073$; model r2: $\Delta \chi^{2}=6.045, \Delta d f=2, p=.049$ ) when comparing these more restrictive models to the earlier model and, moreover, changes in model parameters (i.e., regressions weights) suggest that associations between these variables might not necessarily be same for mothers and fathers and should not be equalized. Therefore, we reported the results of the less restricted final model in Table 2.

\section{H1: Mediating Mechanisms of Shared Time}

The first objective of this study was to test for mediating mechanisms of shared time (H1a). The results of a first model without the mediators included, revealed significant negative associations of mothers' CMES with both mothers' $(b=-.133, S E=$ $.06, p=.024)$ and fathers' $(b=-.131, S E=.06, p=.021)$ relationship satisfaction. At the same time, fathers' CMES was not significantly associated with either of the two outcomes (mothers' RAS: $b=-.025, S E=.07, p=.702$; fathers' RAS: $b=-.073, S E=$ $.06, p=.234$ ). In the final model including the mediators (see Table 2 and Figure 2), the remaining direct effects of mothers' CMES on mothers' or fathers' relationship 


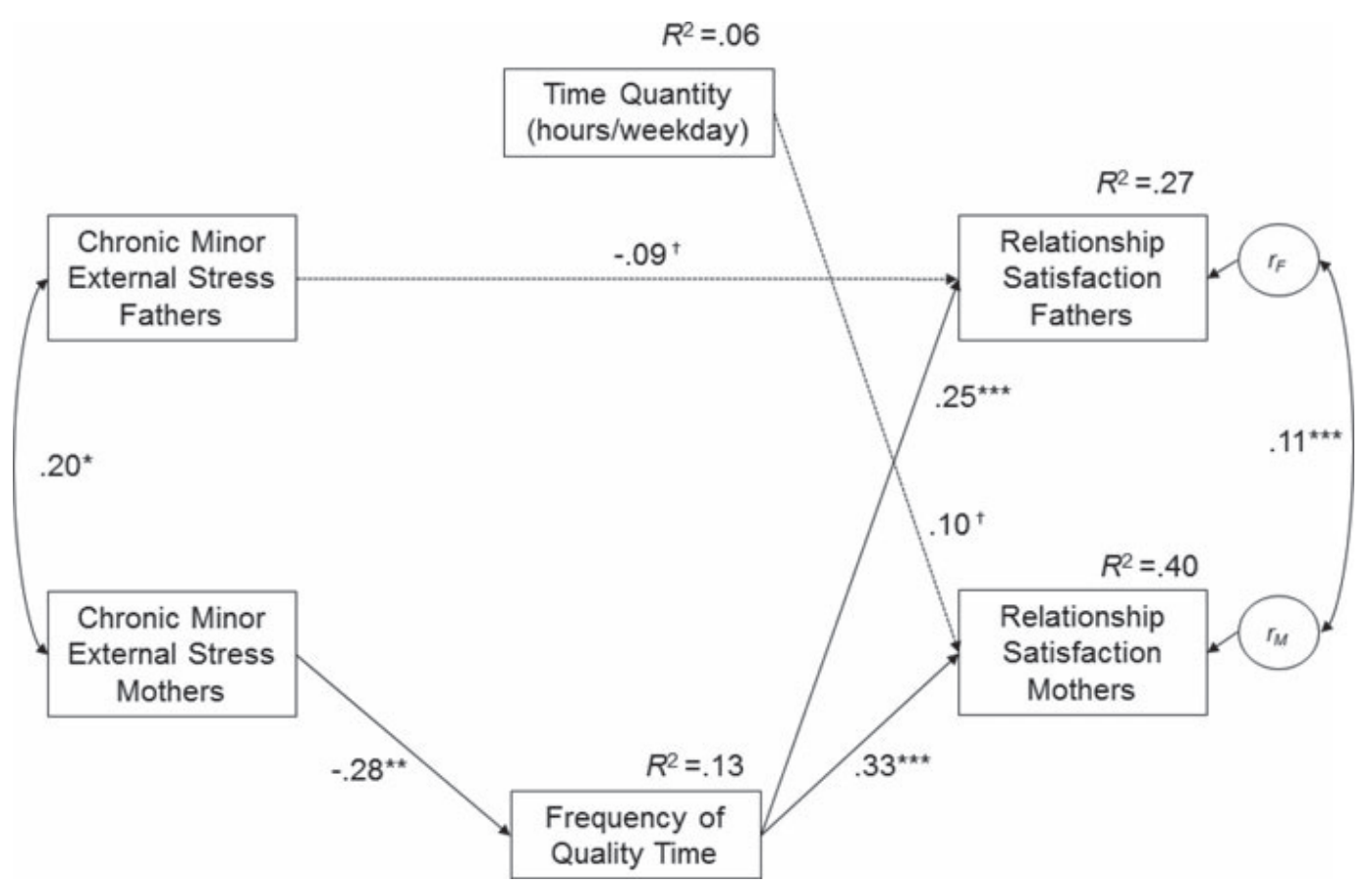

Figure 2. Unstandardized model results of shared time mediating the negative association between chronic minor external stress and relationship satisfaction for fathers and mothers. We controlled for the number of children in the household, the mean age of children, relationship duration and mothers' and fathers' workload. ${ }^{\dagger} p<.10 * p<.05 .{ }^{* *} p<.01 .{ }^{* * *} p<.001$.

satisfaction were not significant, indicating complete mediation. Instead, we found two significant specific indirect effects via quality time (mothers' stress $\rightarrow$ quality time $\rightarrow$ mothers' relationship satisfaction: $b=-.094, S E=.04, p=.025$; mothers' stress $\rightarrow$ quality time $\rightarrow$ fathers' relationship satisfaction: $b=-.070, S E=.04, p=$ .048). None of the indirect effects via time quantity reached statistical significance; therefore, our hypothesis 1a was only partially confirmed.

Hypothesis $1 \mathrm{~b}$ posited that CMES is negatively associated with both dimensions of shared time, which was not confirmed. Mothers' CMES was significantly associated with less quality time as a couple $(b=-.282, S E=.11, p=.007)$ but not time quantity $(b=-.102, S E=.12, p=.388)$. For fathers, path coefficients of CMES on shared time were not significant (quantity: $b=.026, S E=.11, p=.797$; quality: $b=$ $.063, S E=.09, p=.505$ ). More quality time was significantly associated with higher relationship satisfaction for mothers $(b=.331, S E=.06, p<.001)$ as well as for fathers $(b=.247, S E=.07, p<.001)$. More time quantity was marginally significantly associated with higher relationship satisfaction for mothers $(b=.098, S E=$ $.06, p=.080)$ but not fathers $(b=.028, S E=.04, p=.523)$. Thirteen percent of the variance in quality time and $6 \%$ of the variance in time quantity could be explained by mothers' and fathers' stress levels and the control variables included in the model.

\section{H2: Incremental Effects of Time Quantity and Quality Time on Relationship Satisfaction}

Restricting the effects for time quantity and quality time to be equally associated with mothers' relationship satisfaction (and fathers' relationship satisfaction, 
respectively) resulted in a significant decrease in model fit $\left(\Delta \chi^{2}=9.785, \Delta d f=2\right.$, $p=.008$ ). Therefore, time quantity and quality time cannot be considered equally linked to parents' relationship satisfaction (for mothers or fathers). In total, the predictors (including the control variables and CMES) accounted for $40 \%$ of the variance of mothers' relationship satisfaction but for only $27 \%$ of the variance of fathers' relationship satisfaction. For mothers, $25 \%$ of the variance in relationship satisfaction was explained by quality, whereas only $3 \%$ was explained by time quantity above and beyond all other predictors in the model. For fathers, quality time explained $15 \%$ and time quantity explained $1 \%$ of additional variance in relationship satisfaction. In accord with our hypothesis, the frequency of quality time was more strongly associated with relationship satisfaction and explained a greater share of variance in relationship satisfaction than time quantity.

\section{H3: Gender Difference in the Importance of Shared Time}

As mentioned here earlier, associations between CMES and shared time differed between mothers and fathers; thus, hypothesis $\mathrm{H} 3$ was supported. Model fit significantly decreased when path coefficients of CMES on shared time and shared time on parents' relationship satisfaction were restricted to be equal across genders. When all other variables were controlled for, mothers' path coefficients for quality time on relationship satisfaction were substantially greater in magnitude in comparison to fathers', or with respect to time quantity even marginally significantly positive in comparison to a nonsignificant association for fathers (see Table 2). In contrast to the results for mothers, we did not find any indirect effects from fathers' CMES by means of quality time on parents' relationship satisfaction (fathers' chronic minor external stress $\rightarrow$ quality time $\rightarrow$ mothers' relationship satisfaction: $b=.021, S E$ $=.03, p=.510$; fathers' chronic minor external stress $\rightarrow$ quality time $\rightarrow$ fathers' relationship satisfaction: $b=.016, S E=.02, p=.522)$. In addition, shared time explained more variance in mothers' than in fathers' relationship satisfaction.

\section{Discussion}

The purpose of this study was to differentiate the ways in which shared time-in both quantity and quality-uniquely contribute to parents' relationship satisfaction in the presence of CMES. The negative associations between mothers' CMES and their own and their partners' relationship satisfaction were completely mediated via a reduction in the reported frequency of quality time activities but not via a reduction of the quantity of shared time itself. We did not find such indirect effects for fathers' CMES. These results provide preliminary support for the notion that mothers', but not fathers', CMES load may be associated with fewer reported quality time activities, which were also associated with lower reports of relationship satisfaction for both mothers and fathers. As proposed by Bodenmann's (2000) stress-divorce model, a reduction in shared time might be one of many different pathways through which stress can have deleterious effects on relational well-being. Interestingly, rather than 
the amount of shared time per se, only the reported frequency of shared quality time activities seemed to be linked to stress for couples in this sample. Below we will discuss these effects in further detail.

\section{Quantity Versus Quality}

Providing support for prior findings (e.g., Aron \& Aron, 1986; Berg et al., 2001; Johnson et al., 2006), our results suggest that it is not the mere quantity of time, but rather how couples spent time together that is associated with mothers' and fathers' relationship satisfaction. Mothers who reported more CMES did not spend less time with their partners per se, but engaged in fewer shared quality time activities, and were less satisfied with their relationship. Even more importantly, we found actor and partner effects, such that both their own (mother's) and their partner's (father's) reports of relationship satisfaction were associated with less shared quality time due to mothers' external stress. Interestingly, we did not find the same results for fathers' external stress.

Overall, shared time appeared to be more important for mothers' relationship satisfaction (compared to fathers'), which replicates prior research by Smith and colleagues (1988). Our findings emphasize the necessity of distinguishing the quantity of time a couple spends together from the frequency of quality time, as these two variables were differently associated with parents' CMES and were linked to mothers' and fathers' relationship satisfaction to different degrees.

\section{Effects of External Stress on Time Quantity}

In contrast to our hypothesis, mothers' and fathers' CMES were not associated with time quantity: More stressed couples did not report spending less time with their partners. One possible explanation for this finding could be that in a functional romantic relationship, fathers, as well as mothers, may actively seek their partner's support during periods of high external stress. The skill of supporting one's partner in stressful times and coping with external stressors together as a couple is known to be one of the most important predictors of relationship satisfaction (Falconier, Jackson, Hilpert, \& Bodenmann, 2015). Further research is necessary to shed light on whether skills like stress communication (e.g., withdrawal patterns) or individual and dyadic coping skills may moderate the effect of stress on and the use of shared time.

\section{Gender Differences}

We found significant gender differences for the associations between CMES and shared time. When fathers reported higher levels of CMES, couples did not necessarily spend less (quality) time with one another, assuming a mean level of mothers' external stress load and average values in other variables. Considering the significant gender gap in paid employment in Germany (German Federal Employment Agency, 2015), one possible explanation for this striking gender difference might be that mothers' and fathers' CMES stem from different sources. For example, fathers might 
experience more stress outside the home from work, such as meeting a project deadline, whereas mothers might be predominantly faced with domestic stress, such as going grocery shopping or completing household chores. Nondomestic and domestic stressors are likely to be differently associated with the daily amount of (quality) time parents spent together. For example, mothers still do the major part of child rearing and the daily routine housework (Coltrane, 2000) and enjoy about $30 \mathrm{~min}$ utes less free time each day (Mattingly \& Sayer, 2006), which makes it harder for them to perceive time at home as enjoyable as men do (Larson, Gillman, \& Richards, 1997). Therefore, the more stress a mother experiences at home the less likely she will be able to engage in quality time activities. However, future research needs to examine whether this pattern is related to gender differences or a result of a family role enacted predominately by women in heterosexual couples. Replicating the study with families with less traditional family models or same-sex couples with children would enhance our understanding of the association between shared time and relationship satisfaction for all couples.

Providing psychoeducation to couples on the influence of stress on couples is an essential technique in couple therapy (Milek \& Bodenmann, 2016). Based on the current results, clinicians might consider informing "stressed" heterosexual couples with children that it is specifically the mothers' chronic stress that may be linked to less quality time for the couple, which in turn is linked to less relationship satisfaction for both partners. Exploring whether couples can relate to this spillover pathway and gaining a deeper temporal understanding of the links between external stress and shared time would also allow clinicians to integrate suitable time-centered interventions into therapy sessions and relationship education programs. For example, Fraenkel and Wilson (2000) suggest a variety of time-centered exercises that help couples build awareness about temporal patterns, affirm acceptable, or alter unsatisfactory ones. Additionally, strengthening the couple's skill to cope together with external stressors-using even little shared time effectively to support each othermay be a promising avenue to help couples dealing with increasing rates of time pressure and external stress. Empirical evidence provides support for the efficacy of coping-oriented therapy and prevention programs for couples (e.g., Couples Coping Enhancement Training, CCET; Bodenmann \& Shantinath, 2004; TOGETHER; Falconier, 2015). In addition to traditional elements of couples programs (e.g., communication and problem-solving skills), coping-oriented therapy and prevention programs explicitly address dyadic coping skills (e.g., fostering stress communication, decreasing negative and increasing positive support behaviors) in promoting relationship satisfaction and reducing marital distress.

\section{Limitations and Future Directions}

Several limitations need to be taken into consideration when interpreting the current findings. First, most of the German couples in this study were married for longer than 20 years, were fairly satisfied with their relationship, and were parents 
of children aged 15 or older, underrepresenting newlywed couples with young children or unhappy couples, who all may spend and perceive shared time very differently. Therefore, the composition of the sample limits the generalizability of the results. More data from parents at different life stages and across cultures are needed, before final inferences about the associations between CMES, shared time, and relationship satisfaction can be drawn. Second, data were collected using self-reports, which are subject to personal bias. Additionally, the subjective chronic stress load was assessed with one general item only. Even though Gardner, Cummings, Dunham, and Pierce (1998) found that well-developed single-item measures might be as appropriate as multiple-item measures in certain circumstances and Elo, Leppänen, and Jahkola (2003) demonstrated the validity of a similar single-item stress measure, using a single-item measure prevents the explicit testing of the reliability of the construct. As such, gathering detailed information about the particular origin(s) of the chronic minor external stressors would be helpful to enhance our understanding about cultural and gender differences in spillover mechanisms (see Falconier, Randall, \& Bodenmann, 2016). One promising area for future research is to collect more objective measures during real-time. For example, the use of ambulatory assessment like electronic diaries or naturalistic sampling (e.g. EAR; Mehl \& Holleran, 2007) would allow researchers to assess time measures more reliably and compare intraindividual and interindividual influences of shared time on relationship outcomes on stressful days with days when partners experience less external stress. Third, although statistical analyses of association can provide evidence of mediation pathways (see Shrout \& Bolger, 2002), the models tested cannot establish causal links. Due to the cross-sectional design of our study, even though differences in associations and explanations of variances can be interpreted, reported statistical paths cannot be interpreted as causal paths. Theory suggests that external stress and shared time influence relationship processes (e.g., Bodenmann, 2000); however, the alternative interpretation that highly satisfied couples are motivated to spend more time together and might perceive external stressors as less stressful has substantial merit. To adequately test for causal relations, it would be preferable to assess the predictors at Time 1, mediators at Time 2, and the outcomes at Time 3, controlling for initial levels of the mediators and outcomes (see Cole \& Maxwell, 2003). Further studies should gather longitudinal data at several points of measurement from both partners to specifically address causal links between external stress, shared time, and relationship satisfaction.

\section{Conclusion}

Mothers' and fathers' perceptions of the frequency of quality time spent together may mediate the deleterious effects of CMES on parents' relationship satisfaction. The empirical results suggest that it may primarily be mothers' CMES that accounts for decrements in quality time and both mother's and father's relationship satisfaction. Disentangling dimensions of shared time, and analyzing the unique impact of 
CMES on different relational outcomes, such as trust, commitment, and satisfaction using longitudinal data might be a fruitful approach to further enhance our understanding of deleterious spillover effects of stress. Furthermore, discriminating between different sources of minor external stress, as well as examining how external stress and dimensions of shared time are associated with other important factors of couple functioning (e.g., dyadic coping or effective parenting) may reveal important knowledge on detrimental spillover processes for both relationship researchers and clinicians working with couples.

Specifically, clinicians should bear in mind that just enhancing the quantity of shared time together without simultaneously considering the time quality, may have "at best no association with, and at worst a negative association with, marital satisfaction" (Holman \& Jacquart, 1988, p. 76). Establishing habitual moments of quality time amid stressful periods may be a fruitful way to preserve parents' relationship satisfaction.

\section{Note}

1. Partners' responses on how many hours they spent together during the weekend were significantly correlated by $r=.58$. On average over the entire week, mothers reported approximately 30 minutes less shared time compared to fathers.

\section{References}

Aiken, L. S., \& West, S. G. (1991). Multiple regression: Testing and interpreting interactions. Newbury Park, CA: Sage.

Amato, P. R., Booth, A., Johnson, D. R., \& Rogers, S. J. (2007). Alone together: How marriage in America is changing. Cambridge, MA: Harvard University Press.

American Psychological Association. (2011). Stress and gender. Retrieved from http://www.apa.org/news/press/releases/stress/2011/gender.aspx

Aron, A., \& Aron, E. N. (1986). Love and the expansion of self: Understanding attraction and satisfaction. New York: Hemisphere Publishing.

Aron, A., Norman, C. C., Aron, E. N., McKenna, C., \& Heyman, R. E. (2000). Couples' shared participation in novel and arousing activities and experienced relationship quality. Journal of Personality and Social Psychology, 78(2), 273-284. http://doi.org/10.1037/0022-3514.78.2.273

Bakker, A. B., Demerouti, E., \& Schaufeli, W. B. (2005). The crossover of burnout and work engagement among working couples. Human Relations, 58(5), 661-689. http://doi.org/10.1177/0018726705055967

Baxter, L. A., \& Dindia, K. (1990). Marital partners' perceptions of marital maintenance strategies. Journal of Social and Personal Relationships, 7(2), 187-208. http://doi.org/10.1177/0265407590072003

Berg, E. C., Trost, M., Schneider, I. E., \& Allison, M. T. (2001). Dyadic exploration of the relationship of leisure satisfaction, leisure time, and gender to relationship satisfaction. Leisure Sciences, 23(1), 35-46. http://doi.org/10.1080/01490400150502234

Bianchi, S. M. (2000). Maternal employment and time with children: Dramatic change or surprising continuity? Demography, 37(4), 401-414. http://doi.org/10.1353/dem.2000.0001

Bodenmann, G. (1995). A systemic-transactional view of stress and coping in couples. Swiss Journal of Psychology, 54(1), 34-49. 
Bodenmann, G. (2000). Stress und Coping bei Paaren [Stress and coping in couples]. Göttingen: Hogrefe.

Bodenmann, G., Charvoz, L., Bradbury, T. N., Bertoni, A., Lafrate, R., Giuliani, C., ... Behling, J. (2007). The role of stress in divorce: A three-nation retrospective study. Journal of Social and Personal Relationships, 24(5), 707-728. http://doi.org/10.1177/0265407507081456

Bodenmann, G., \& Shantinath, S. D. (2004). The Couples Coping Enhancement Training (CCET): A new approach to prevention of marital distress based upon stress and coping. Family Relations, 53(5), 477-484. http://doi.org/10.1111/j.0197-6664.2004.00056.x

Buck, A. A., \& Neff, L. A. (2012). Stress spillover in early marriage: The role of self-regulatory depletion. Journal of Family Psychology, 26(5), 698-708. http://doi.org/10.1037/a0029260

Claxton, A., \& Perry-Jenkins, M. (2008). No fun anymore: Leisure and marital quality across the transition to parenthood. Journal of Marriage and Family, 70(1), 28-43. http://doi.org/10.1111/j.1741-3737.2007.00459.x

Cole, D. A., \& Maxwell, S. E. (2003). Testing mediational models with longitudinal data: Questions and tips in the use of structural equation modeling. Journal of Abnormal Psychology, 112(4), 558-577. http://doi.org/10.1037/0021-843X.112.4.558

Coltrane, S. (2000). Research on household labor: Modeling and measuring the social embeddedness of routine family work. Journal of Marriage and the Family, 62(4), 1208-1233. http://doi.org/10.1111/j.1741-3737.2000.01208.x

Conger, R. D., Elder, G. H., Lorenz, F. O., Conger, K. J., Simons, R. L., Whitbeck, L. B., ... Melby, J. N. (1990). Linking economic hardship to marital quality and instability. Journal of Marriage and the Family, 52(3), 643. http://doi.org/10.2307/352931

Coyne, J. C., \& Smith, D. A. (1991). Couples coping with a myocardial infarction: A contextual perspective on wives' distress. Journal of Personality and Social Psychology, 61, 404-412. http://doi.org/10.1037/0022-3514.61.3.404

Crawford, D. W., Houts, R. M., Huston, T. L., \& George, L. J. (2002). Compatibility, leisure, and satisfaction in marital relationships. Journal of Marriage and Family, 64(2), 433-449. http://doi.org/10.1111/j.1741-3737.2002.00433.x

Daly, K. J. (2001). Deconstructing family time: From ideology to lived experience. Journal of Marriage and Family, 63(2), 283-294. http://doi.org/10.1111/j.1741-3737.2001.00283.x

Dew, J. (2009). Has the marital time cost of parenting changed over time? Social Forces, 88(2), 519-541. http://doi.org/10.1353/sof.0.0273

Dinkel, A., \& Balck, F. (2005). An evaluation of the German Relationship Assessment Scale. Swiss Journal of Psychology, 64(4), 259-263. http://doi.org/10.1024/1421-0185.64.4.259

Elo, A.-L., Leppänen, A., \& Jahkola, A. (2003). Validity of a single-item measure of stress symptoms. Scandinavian Journal of Work, Environment \& Health, 29(6), 444-451. http://doi.org/10.5271/sjweh.752

Eurostat. (2012). Labour Market Earnings Database. Luxembourg: Statistical Office of the European Communities. Retrieved from Available at http://epp.eurostat.ec.europa.eu/portal/page/portal/labour_market/earnings.

Falconier, M. K. (2015). TOGETHER-A couples' program to improve communication, coping, and financial management skills: Development and initial pilot-testing. Journal of Marital and Family Therapy, 41(2), 236-250. doi:10.1111/jmft.12052

Falconier, M. K., Jackson, J. B., Hilpert, P., \& Bodenmann, G. (2015). Dyadic coping and relationship satisfaction: A meta-analysis. Clinical Psychology Review, 42, 28-46. http://doi.org/10.1016/j.cpr.2015.07.002

Falconier, M. K., Randall, A. K., \& Bodenmann, G. (Eds.). (2016). Couples coping with stress: A cross-cultural perspective. New York: Routledge.

Flora, J., \& Segrin, C. (1998). Joint leisure time in friend and romantic relationships: The role of activity type, social skills and positivity. Journal of Social and Personal Relationships, 15(5), 711-718. http://doi.org/10.1177/0265407598155009 
Fraenkel, P. (2001). The place of time in couple and family therapy. In K. J. Daly (Ed.), Minding the time in family experience: Emerging perspectives and issues (pp. 283-310). Amsterdam: JAI.

Fraenkel, P., \& Wilson, S. (2000). Clocks, calendars, and couples: Time and rhythms of relationships. In P. Papp (Ed.), Couples on the fault line: New directions for therapists (pp. 68-90). New York, NY: Guilford Press.

Gager, C. T., \& Sanchez, L. (2003). Two as one?: Couples' perceptions of time spent together, marital quality, and the risk of divorce. Journal of Family Issues, 24(1), 21-50. http://doi.org/10.1177/0192513X02238519

Gardner, D. G., Cummings, L. L., Dunham, R. B., \& Pierce, J. L. (1998). Single-item versus multiple-item measurement scales: An empirical comparison. Educational and Psychological Measurement, 58(6), 898-915. http://doi.org/10.1177/0013164498058006003

German Federal Employment Agency. (2015). Statistik/Arbeitsmarktberichterstattung: Der Arbeitsmarkt in Deutschland: Frauen und Männer am Arbeitsmarkt 2014 [Statistics/ labor market report: The labor market in Germany: Women and men in the labor market in 2014]. Nürnberg: Author. Retrieved from http://statistik.arbeitsagentur.de/ nn_10772/SiteGlobals/Forms/Suche/serviceSuche_Form.html?allOfTheseWords=Der+Arb eitsmarkt+in+Deutschland+++Frauen+und+M\%C3\%A4nner+am+Arbeitsmarkt+2014\&pa geLocale $=$ de\&view $=$ processForm

Gershuny, J. (2000). Changing times: Work and leisure in postindustrial society. Oxford: Oxford University Press.

Gottlieb, B. H., \& Wagner, E. (1991). Stress and support processes in close relationships. In J. Eckenrode (Ed.), The social context of coping (pp. 165-188). New York: Plenum.

Hamermesh, D. S. (2000). Working Paper 7455. Togetherness: Spouses synchronous leisure, and the impact of children. Cambridge, MA: National Bureau of Economic Research.

Hamermesh, D. S. (2008). The time of our lives. In J. Kimmel (Ed.), How do we spend our time? Evidence from the American Time Use Survey. Kalamazoo, MI: W.E. Upjohn Institute for Employment Research. Retrieved from http://research.upjohn.org/up_press/148/

Hatch, L. R., \& Bulcroft, K. (2004). Does long-term marriage bring less frequent disagreements? Five explanatory frameworks. Journal of Family Issues, 25(4), 465-495. http://doi.org/10.1177/0192513X03257766

Hayes, A. F., \& Preacher, K. J. (2010). Quantifying and testing indirect effects in simple mediation models when the constituent paths are nonlinear. Multivariate Behavioral Research, 45(4), 627-660. http://doi.org/10.1080/00273171.2010.498290

Hendrick, S. S. (1988). A generic measure of relationship satisfaction. Journal of Marriage and Family, 50(1), 93-98. http://doi.org/10.2307/352430

Hill, M. S. (1988). Marital stability and spouses' shared time: A multidisciplinary hypothesis. Journal of Family Issues, 9, 427-451. http://doi.org/10.1177/019251388009004001

Hochschild, A. R. (1997). The time bind: When work becomes home and home becomes work. New York: Metropolitan Books.

Holman, T. B., \& Epperson, A. (1984). Family and leisure: A review of the literature with research recommendations. Journal of Leisure Research, 16(4), 277-294.

Holman, T. B., \& Jacquart, M. (1988). Leisure-activity patterns and marital satisfaction: A further test. Journal of Marriage and the Family, 50(1), 69-77. http://doi.org/10.2307/352428

Hu, L., \& Bentler, P. M. (1999). Cutoff criteria for fit indexes in covariance structure analysis: Conventional criteria versus new alternatives. Structural Equation Modeling: A Multidisciplinary Journal, 6(1), 1-55. http://doi.org/10.1080/10705519909540118

Huston, T. L., McHale, S. M., \& Crouter, A. C. (1986). When the honeymoon's over: Changes in the marriage relationship over the first source. In R. Gilmour \& S. Duck (Eds.), The emerging field of personal relationships (pp. 109-132). Hillsdale, NJ: Erlbaum.

Johnson, H. A., Zabriskie, R. B., \& Hill, B. (2006). The contribution of couple leisure involvement, leisure time, and leisure satisfaction to marital satisfaction. Marriage and Family Review, 40(1), 69-91. http://doi.org/10.1300/J002v40n01_05 
Jurczyk, K., \& Heitkötter, M. (2012). Keine Zeit zu zweit: Der Übergang in Elternschaft strapaziert die Paarbeziehung. [No time as a couple: The transition to parenthood impairs the intimate relationship]. DJI Impulse, 97(1), 31-33.

Karney, B. R., \& Bradbury, T. N. (1995). The longitudinal course of marital quality and stability: A review of theory, method, and research. Psychological Bulletin, 118(1), 3-34. http://doi.org/10.1037/0033-2909.118.1.3

Kelly, J. R. (1975). Life styles and leisure choices. The Family Coordinator, 24(2), 185-190. http://doi.org/10.2307/582283

Kelly, J. R. (1980). Outdoor recreation participation: A comparative analysis. Leisure Sciences, 3(2), 129-154. http://doi.org/10.1080/01490408009512931

Kenny, D. A. (1996). Models of nonindependence in dyadic research. Journal of Social and Personal Relationships, 13(2), 279-294. http://doi.org/10.1177/0265407596132007

Kenny, D. A., \& Cook, W. (1999). Partner effects in relationship research: Conceptual issues, analytic difficulties, and illustrations. Personal Relationships, 6(4), 433-448. http://doi.org/10.1111/j.1475-6811.1999.tb00202.x

Kilbourne, B. S., Howell, F., \& England, P. (1990). A measurement model for subjective marital solidarity: Invariance across time, gender, and life cycle stage. Social Science Research, 19(1), 62-81. http://doi.org/10.1016/0049-089X(90)90015-B

King, D. B., \& DeLongis, A. (2014). When couples disconnect: Rumination and withdrawal as maladaptive responses to everyday stress. Journal of Family Psychology, 28(4), 460-469. http://doi.org/10.1037/a0037160

Kingston, P. W., \& Nock, S. L. (1987). Time together among dual-earner couples. American Sociological Review, 52(3), 391-400. http://doi.org/10.2307/2095358

Kirchler, E. (1988). Marital happiness and interaction in everyday surroundings: A time-sample diary approach for couples. Journal of Social and Personal Relationships, 5(3), 375-382. http://doi.org/10.1177/0265407588053007

Larson, R. W., Gillman, S. A., \& Richards, M. H. (1997). Divergent experiences of family leisure: Fathers, mothers, and young adolescents. Journal of Leisure Research, 29(1), 78-97.

Ledermann, T., Bodenmann, G., Rudaz, M., \& Bradbury, T. N. (2010). Stress, communication, and marital quality in couples. Family Relations, 59(2), 195-206. http://doi.org/10.1111/j.17413729.2010.00595.x

Ledermann, T., Macho, S., \& Kenny, D. A. (2011). Assessing mediation in dyadic data using the actor-partner interdependence model. Structural Equation Modeling: A Multidisciplinary Journal, 18(4), 595-612. http://doi.org/10.1080/10705511.2011.607099

Lenz, K. (2009). Zeit für und Zeit in Zweierbeziehungen [Time within intimate relationships]. In M. Heitkötter, K. Jurczyk, A. Lange, \& U. Meier-Gräwe (Eds.), Zeit für Beziehungen? Zeit und Zeitpolitik für Familien. (pp. 113-136). Opladen: Budrich.

Levine, R. (1997). A geography of time: The temporal misadventures of a social psychologist, or how every culture keeps time just a little bit differently. New York: Basic Books.

Matos, K., \& Galinsky, E. (2010). Workplace flexibility in the United States: A status report. Families and Work Institute. Retrieved from http://familiesandwork. org/site/research/reports/main.html

Mattingly, M. J., \& Sayer, L. C. (2006). Under pressure: Gender differences in the relationship between free time and feeling rushed. Journal of Marriage and Family, 68(1), 205-221. http://doi.org/10.1111/j.1741-3737.2006.00242.x

Matud, M. P. (2004). Gender differences in stress and coping styles. Personality and Individual Differences, 37(7), 1401-1415. http://doi.org/10.1016/j.paid.2004.01.010

Mehl, M. R., \& Holleran, S. E. (2007). An empirical analysis of the obtrusiveness of and participants' compliance with the Electronically Activated Recorder (EAR). European Journal of Psychological Assessment, 23(4), 248-257. http://doi.org/10.1027/1015-5759.23.4.248 
Milek, A., \& Bodenmann, G. (2016). Psycho-education on the influence of stress on couples. In G. R. Weeks \& S. T. Fife (Eds.), Techniques for the couple therapist: Essential interventions (pp. 227-230). New York: Routledge.

Milek, A., Butler, E. A., \& Bodenmann, G. (2015). The interplay of couple's shared time, women's intimacy, and intra-dyadic stress. Journal of Family Psychology, 29(6), 831-842. http://doi.org/10.1037/fam0000133

Miller, B. C. (1976). A multivariate developmental model of marital satisfaction. Journal of Marriage and the Family, 38(4), 643-657. http://doi.org/10.2307/350684

Muthén, L. K., \& Muthén, B. O. (1998-2012). Mplus User's Guide. (7th ed.). Los Angeles, CA: Muthén \& Muthén.

Neff, L., \& Karney, B. (2004). How does context affect intimate relationships? Linking external stress and cognitive processes within marriage. Personality and Social Psychology Bulletin, 30(2), 134-148. http://doi.org/10.1177/0146167203255984

Orthner, D. K. (1975). Leisure activity patterns and marital satisfaction over the marital career. Journal of Marriage and the Family, 37(1), 91-102. http://doi.org/10.2307/351033

Randall, A. K., \& Bodenmann, G. (2017). Stress and its associations with relationship satisfaction. Current Opinion in Psychology, 13, 96-106. https://doi.org/10.1016/j.copsyc.2016.05.010

Randall, A. K., \& Bodenmann, G. (2009). The role of stress on close relationships and marital satisfaction. Clinical Psychology Review, 29(2), 105-115. http://doi.org/10.1016/j.cpr.2008.10.004

Reissman, C., Aron, A., \& Bergen, M. R. (1993). Shared activities and marital satisfaction: Causal direction and self-expansion versus boredom. Journal of Social and Personal Relationships, 10(2), 243-254. http://doi.org/10.1177/026540759301000205

Repetti, R. (1989). Effects of daily workload on subsequent behavior during marital interaction: The roles of social withdrawal and spouse support. Journal of Personality and Social Psychology, 57(4), 651-659. http://doi.org/10.1037/0022-3514.57.4.651

Repetti, R., Wang, S., \& Saxbe, D. (2009). Bringing it all back home: How outside stressors shape families' everyday lives. Current Directions in Psychological Science, 18(2), 106-111. http://doi.org/10.1111/j.1467-8721.2009.01618.x

Robinson, J. P., \& Godbey, G. (1998). Trend, gender, and status differences in Americans' perceived stress. Loisir et société/Society and Leisure, 21(2), 473-489. http://doi.org/10.1080/07053436.1998.10753665

Roxburgh, S. (2002). Racing through life: The distribution of time pressures by roles and role resources among full-time workers. Journal of Family and Economic Issues, 23(2), 121-145. http://doi.org/10.1023/A:1015734516575

Roxburgh, S. (2006). "I wish we had more time to spend together...": The distribution and predictors of perceived family time pressures among married men and women in the paid labor force. Journal of Family Issues, 27(4), 529-553. http://doi.org/10.1177/0192513X05284008

Shrout, P., \& Bolger, N. (2002). Mediation in experimental and nonexperimental studies: New procedures and recommendations. Psychological Methods, 7(4), 422-445. http://doi.org/10.1037/1082-989X.7.4.422

Smith, G., Synder, D. K., Trull, T. J., \& Monsma, B. R. (1988). Predicting relationship satisfaction from couples' use of leisure time. American Journal of Family Therapy, 16(1), 3-13. http://doi.org/10.1080/01926188808250702

Tamres, L. K., Janicki, D., \& Helgeson, V. S. (2002). Sex differences in coping behavior: A metaanalytic review and an examination of relative coping. Personality and Social Psychology Review, 6(1), 2-30. http://doi.org/10.1207/S15327957PSPR0601_1

Thorn, L., Hucklebridge, F., Evans, P., \& Clow, A. (2006). Suspected nonadherence and weekend versus week day differences in the awakening cortisol response. Psychoneuroendocrinology, 31(8), 1009-1018. http://doi.org/10.1016/j.psyneuen.2006.05.012 
Voorpostel, M., van der Lippe, T., \& Gershuny, J. (2010). Spending time together-changes over four decades in leisure time spent with a spouse. Journal of Leisure Research, 42(2), 243-265.

White, L. K. (1983). Determinants of spousal interaction: Marital structure or marital happiness. Journal of Marriage and Family, 45(3), 511-519. http://doi.org/10.2307/351656

Wight, V. R., Raley, S. B., \& Bianchi, S. M. (2008). Time for children, one's spouse and oneself among parents who work nonstandard hours. Social Forces, 87(1), 243-271. http://doi.org/10.1353/sof.0.0092

Witt, P. A., \& Goodale, T. L. (1981). The relationships between barriers to leisure enjoyment and family stages. Leisure Sciences, 4(1), 29-49. http://doi.org/10.1080/01490408109512948

Zabriskie, R. B., \& McCormick, B. P. (2001). The influences of family leisure patterns on perceptions of family functioning. Family Relations, 50(3), 281-289. http://doi.org/10.1111/j.17413729.2001.00281.x 